\title{
A PSicologia Ambiental: COMPETÊNCIA E CONTORNOS DE UMA DisCIPLINA. COMENTÁRIOS A PARTIR DAS CONTRIBUIÇÕES
}

\author{
Gabriel Moser ${ }^{1}$ \\ Universidade Paris $V$
}

Este texto apresenta uma síntese reflexiva e crítica a respeito dos temas do Simpósio Internacional Psicologia e Ambiente, conforme desenvolvidos pelos sucessivos participantes. Inicia pela questão da unidade da psicologia ambiental focalizando o seu obje to, o seu papel e a sua utilidade; a seguir, discute a psicologia ambiental entre a afirmação disciplinar e a errância pluridisciplinar; e, ao enfocar o tema psicologia ambiental e políticas públicas, propõe marcos de referência para uma visibilidade política eficaz. À guisa de conclusão, apresenta um programa para o futuro.

Descritores: Psicologia ambiental. Pesquisa interdisciplinar. Políticas públicas.

$\mathrm{O}$ Simpósio de São Paulo sobre "Psicologia e Ambiente", cujos textos foram aqui apresentados, foi organizado em torno de três questões fundamentais: 1) Qual é objeto da Psicologia Ambiental face à diversidade? 2) Como se situa a Psicologia Ambiental em relação a uma abordagem pluridisciplinar do conhecimento?, e 3) Qual é a relação entre Psicologia Ambiental e Política Ambiental? A resposta à primeira questão condiciona, de algum modo, as respostas à segunda e, sobretudo, à terceira questão. Propor

1 Professor de Psicologia Ambiental e coordenador do programa de Especialização em Psicologia Ambiental da Universidade de Paris V, França. Diretor do Laboratório de Psicologia Ambiental do Centro Nacional de Pesquisa Científica da França; membro da diretoria da IAPS. Endereço eletrônico: gabriel.moser@univ-paris5.fr 
estas interrogações e discutilas com especialistas originários da América Latina, da América do Norte e da Europa poderá, certamente, ampliar o debate quanto à posição da psicologia ambiental face às questões da cultura, dimensão cuja consideração em nossa disciplina é fundamental.

\section{A unidade da Psicologia Ambiental em questão, ou como desenter- rar velhos demônios}

Como acentua M. V. Giuliani, a Psicologia Ambiental parece colocar um problema mesmo para aqueles que trabalham na área. Qual é a identidade da Psicologia Ambiental? Tem ela uma unicidade, além da diversidade de suas abordagens? ? $^{2}$ Colocar a questão do objeto da Psicologia Ambiental face à diversidade das realidades humanas, como está precisado na introdução ao simpósio, subentende que poderia haver aí não apenas uma psicologia ambiental, mas Psicologias Ambientais. Ora, este ponto de vista, que não é novo em psicologia ${ }^{3}$, é perigoso na medida em que ele ameaça a própria unidade da disciplina e, em consequência, também a sua sobrevivência. Na leitura das diferentes contribuições do primeiro dia parece haver, com efeito, uma certa confusão entre o objeto de nossa disciplina, as temáticas às quais ela é levada a se interessar e os procedimentos científicos utilizados para adquirir os conhecimentos necessários e específicos à disciplina. Resulta daí também uma certa ambigüidade quanto ao seu papel e à maneira como deve funcionar a disciplina.

a) O objeto da psicologia ambiental

A Psicologia Ambiental é uma disciplina que trata do "psicológico", quer dizer, do indivíduo enquanto ser que pensa, que sente e que age, de um

2 Este primeiro tópico se baseia nas contribuições de E. Wiesenfeld, V. Giuliani, E. Rabinovich, G. Evans, M. V. Corral e L. Kruse.

3 Ver especialmente os freqüentes debates observados na França entre a Psicologia Clínica e a Psicologia dita "Experimental". 
lado, e do ambiente, de outro lado. Trata-se de Psicologia, portanto de uma disciplina que lida com o indivíduo em sua relação com o ambiente.

Porém aqui termina o consenso. Imediatamente aparecem diferentes concepções da disciplina quando se trata de precisar "o que" estudar e "como" estudar. Assim, para G. Evans, a Psicologia Ambiental é definida como o estudo científico da relação entre o ambiente físico e o comportamento humano. Segundo este autor, toda pesquisa na disciplina deve dirigir-se ao ambiente físico, o único objeto que pode satisfazer as exigências de um método científico e que pode permitir realizarmos a transição entre os nossos discursos e o dos engenheiros que supostamente aplicariam os nossos saberes. Para saber qual é a influência do ambiente físico no comportamento, é preciso distinguir claramente esses dois termos. Isto não implica excluir toda investigação baseada em declarações do indivíduo mas a perceber claramente os seus limites. Igualmente, damos importância demasiada aos fatores culturais. Enquanto psicólogos, colocamos o acento principalmente sobre as diferenças individuais e não o suficiente sobre as diferenças ambientais. Em outros termos, as diferenças interculturais seriam essencialmente devidas às variações ambientais.

Uma tal concepção da Psicologia Ambiental está, obviamente, do lado oposto a uma concepção transacional cujo ponto de partida é o vivido pelo indivíduo. Nesta ótica, o objeto da disciplina é a relação indivíduo-ambiente, os termos indivíduo e ambiente não sendo independentes entre si. Como lembra E. Wiesenfeld, a Psicologia Ambiental tem como objetivo estudar a relação indivíduo-ambiente, abordá-la de um modo holístico, colocar a ênfase na dimensão social desta relação e estabelecer os elos com outras disciplinas interessadas nesta temática. Isto permite defini-la, pois mesmo se as definições não são consensuais, todas aderem a esta noção de "relação indivíduo-ambiente". Este princípio relacional, declinado em termos de interação ou de transação, fornece o quadro de análise da disciplina. Assim, em cada exame da relação com o ambiente, a atenção se dirige tanto ao indivíduo quanto ao próprio ambiente. Pode-se, portanto, definir a Psicologia Ambiental como sendo o estudo das interrelações entre o indivíduo e seu ambiente físico e social, nas suas dimensões espaciais e temporais. 
Como salienta L. Kruse, a noção de ambiente nas Ciências Sociais não é a mesma das Ciências da Natureza. Nas Ciências Sociais, o ambiente é geralmente considerado como uma construção daquele que o percebe. De modo evidente, a dimensão cultural está presente na relação com o ambiente. $\mathrm{O}$ enquadramento ambiental não é um espaço neutro e isento de valores, ele é culturalmente marcado. As análises em termos de comportamentos compatíveis com um desenvolvimento durável são confrontadas, de modo recorrente, às diferenças culturais (cf. Corral). $\mathrm{O}$ ambiente, enquanto tal, veicula significações; nossa visão da natureza humana se exprime na maneira como nós moldamos o espaço construído; e este espaço construído retorna a nós, re-significando quem nós somos e o que devemos fazer (Getzel, 1975). A adesão a uma posição determinista, ou mesmo interacionista, conduz certamente a reconhecer que o ambiente tem um efeito direto nas ações do indivíduo, porém o ambiente propicia, antes de tudo, o sentido e a ident idade, situando o indivíduo social, economica e culturalmente. O contexto ambiental, objeto de percepções, de atitudes, e de comportamentos nele manifestados, necessita igualmente da consideração da dimensão temporal (Moser \& Uzzell, 2003). A relação com um espaço dado é, além do presente, tributária de seu passado e do futuro. Os lugares têm um passado que contribui para a sua interpretação atual, e um futuro que é suscetível de nos guiar em nossas ações por meio de nossas representações antecipatórias.

Devido ao seu objeto, a Psicologia Ambiental foi, e é, antes de tudo, uma Psicologia do espaço, na medida em que ela analisa as percepções, as atitudes e os comportamentos do indivíduo em sua relação explícita com o contexto físico e social no qual ele evolui. Desta maneira, a relação indivíduo-ambiente é analisada nos seguintes quatro níveis de referência espacial e social: 1) o micro-ambiente: o espaço privado, a moradia, implicando o indivíduo; 2) os ambientes de proximidade: os espaços partilhados semipúblicos, o habitat coletivo, o bairro, o lugar de trabalho, os parques e os espaços verdes, concernentes à comunidade de proximidade ou de vizinhança; 3) os ambientes coletivos públicos: as cidades, os vilarejos, e os povoamentos diversos, implicando os agregados de indivíduos; e 4) o ambiente global: o ambiente em sua totalidade, construído ou não, os recursos naturais 
e os concernentes à sociedade enquanto tal. Esta distinção é importante porque ela permite analisar a relação indivíduo-ambiente em termos da relação com o ambiente em suas dimensões físicas e precisar as relação com o outro que cada um dos diferentes níveis implica. Com efeito, os problemas cobcados em questão não são os mesmos segundo a escala em que nos situamos e, em consequiência, o mesmo se aplica às modalidades de intervenção com as quais o psicólogo ambiental pode se comprometer.

Na perspectiva de uma definição da Psicologia Ambiental, podemos também, como mostra M. V. Giuliani, enumerar e identificar as preocupações da disciplina segundo a classificação de Stokols (1978), que distingue a transação ativa ou reativa que está implicada na cognição ou no comportamento. Isto permite classificar os grupos de temáticas em: modo interpretativo, modo avaliativo, modo operativo (referente à ação) e modo reativo. Decorre claramente que certas abordagens são mais centradas na aplicação, enquanto outras se inscrevem essencialmente em uma questão acadêmica.

Cada temática inscrita na relação indivíduo-ambiente, em um dos quatro níveis identificados acima, pode se constituir como um objeto de análise em termos de psicologia ambiental, mas não pode ser apenas ela a única identificada com a disciplina. Em outros termos, uma disciplina não poderia ser definida pelas temáticas que a preocupam e, a fortirori, não se limita a uma ou outra dessas temáticas. Assim, a Psicologia Ambiental sobreviveu felizmente à "Psicologia Arquitetural", cara a Canter (1970), e ela sobreviverá à tendência atual identificada como "Psicologia verde" por Pol, como "Psicologia do desenvolvimento durável" por Bonnes e Bonaiuto (2002), ou como "Psicologia da conservação" por certos colegas anglo-americanos. O fato de identificar e singularizar uma Psicologia que lida com os comportamentos em relação ao desenvolvimento durável impede abordar esta problemática em termos de Psicologia Ambiental, quer dizer, de re-situar estes comportamentos em uma problemática mais ampla de relação com o ambiente tal como sugere, por exemplo, o modelo CIS (Cidades, Identidade e Sustentabilidade) de E. Pol. Uma visão fragmentada impede igualmente o uso de uma análise cultural das interações indivíduo-ambiente, cuja utilidade é amplamente mostrada por V. Corral. Certamente, a Psicologia Ambiental 
se alimenta, mais do que outras disciplinas da Psicologia, da demanda social, mas ela adere a paradigmas que vão além da simples respostas a ela.

Pode ser que tais tentações de fragmentação da disciplina advenham de uma certa lacuna mencionada por L. Kruse: o fosso entre as noções teóricas transversais à disciplina e os projetos empíricos. Pelo fato de estar essencialmente preocupada em responder à demanda social, a acumulação e a sistematização dos conhecimentos se tornam secundárias. É ainda L. Kruse quem reivindica pesquisas globais que combinem comportamento e cond utas, de um lado, e cognições e emoções de outro. Este tipo de pesquisa deveria ser, entretanto, preponderante em nossa disciplina, na medida em que é destas abordagens que os avanços teóricos podem se alimentar.

\section{b) papel e utilidade social da Psicologia Ambiental}

A utilidade social da Psicologia Ambiental não está certamente em pauta. O que coloca, aparentemente, um problema é o seu papel, quer dizer, o lugar que se pressupõe que ela ocupa. Podemos opor uma Psicologia Ambiental que seria uma disciplina exclusivamente científica, ocupada com a acumulação de conhecimentos teóricos, a uma Psicologia centrada na resolução de problemas e na intervenção? Aqui, igualmente, encontramo-nos levados a um debate que tem, em psicologia, um sabor requentado. Ele remete, com efeito, a uma eterna distinção entre uma Psicologia fundamental, pouco preocupada com a aplicação, de um lado, e uma Psicologia aplicada ou uma aplicação da Psicologia, de outro. Isto permite a alguns estudiosos identificar dois tipos de Psicologia: as científicas (puras e desinteressadas), e as profissionais, algumas vezes descritas como «comerciantes». Se tal distinção pode ter um certo sentido em Psicologia Geral, ela é, ao contrário, completamente absurda quando se trata de uma disciplina indutiva como a Psicologia Ambiental. É possível imaginar uma Psicologia Ambiental que se limite a construir seus conhecimentos em laboratório? Certamente não. Obviamente, a Psicologia Ambiental deve, mais do que outras disciplinas, procurar um compromisso entre a pesquisa fundamental e a pesquisa aplicada, mas não escapará nunca da crítica de alguns autores que lastimam que a 
psicologia ambiental esteja mais centrada em problemáticas do que na (ou nas) teoria(s), quer dizer, que ela procuraria antes de tudo construir instrumentos para a intervenção (Darley \& Gilbert, 1985).

Do mesmo modo, não se pode argumentar sobre especificidades psico-ambientais diferentes tomando como ponto de partida lógicas metodológicas que se opõem ou seriam incompatíveis. Propondo a abordagem construtivista como alternativa à abordagem transicional, E. Wiesenfeld se refere à importância da ação e da intervenção em psicologia ambiental. Consideramos este método não como uma alternativa mas como um enriquecimento que permite contribuir, de um modo diferente, à construção de conhecimentos da disciplina. Não caiamos na eterna armadilha da oposição entre métodos qualitativos e métodos quantitativos; trata-se de um debate estéril e esterilizante do qual os psicólogos são especialmente ávidos. A especificação metodológica apoiada em uma singularidade cultural é uma argumentação desenvolvida igualmente por E. Rabinovich, referida aos processos de subjetivação. A "poética", conceito extremamente interessante na medida em que se inscreve na transação indivíduo-ambiente, dá conta da estruturação individualizante. O próprio princípio desta estruturação, longe de ser uma especificidade brasileira, parece-me justamente universal. É a maneira como ela pode ser evidenciada no Brasil, sua natureza, sua singularidade e sua especificidade, que são brasileiras. Em outros termos, as metodologias desenvolvidas em psicologia ambiental devem possibilitar dar conta das especificidades culturais. Com efeito, a identificação de especificidades culturais só pode ser feita pela comparação entre culturas diferentes, e é precisamente a abordagem da Psicologia Ambiental que permite o interêsse na contextualização das cognições, das emoções e dos comportamentos. Para evidenciar as maneiras culturalmente específicas de pensar o seu lugar de vida, de agir no ambiente, é preciso que elas sejam evidenciadas por meio de métodos culturalmente neutros. As especificidades e diferenças culturais são analisadas por meio de procedimentos científicos que permitem a sua expressão singular, e não independentemente deles. Fazer a diferença entre, de um lado, a coleta de dados a sua sistematização, e de outro lado, a sua interpretação, permite dar o destaque essencial a toda singularidade. 
Na medida em que a Psicologia Ambiental é tanto uma disciplina acadêmica quanto uma abordagem de campo, ela necessariamente se confronta com diferentes culturas. Identificando o seu objeto como sendo o estudo das inter-relações entre o indivíduo e seu ambiente físico e social nas suas dimensões espaciais e temporais, ela oferece os meios de apreender estas relações em contextos culturalmente diferentes e analisá-los enquanto tal. Apenas quando for identificada como uma disciplina singular, com as suas características e os seus paradigmas próprios, assim como com sua originalidade, suas abordagens do ambiente poderão se inscrever em uma pluridisciplinaridade produtiva.

\section{A Psicologia Ambiental entre afirmação disciplinar e errâncias pluridisciplinares}

A questão subjacente às contribuições deste capítulo ${ }^{4}$ é a de saber como se posicionar ou como deve se posicionar a Psicologia Ambiental dentro de uma abordagem pluridisciplinar do ambiente. Além da unidade, discutida no ítem precedente, coloca-se aqui, novamente, o problema da natureza da disciplina e da maneira como ela funciona. Afim de examinar este ponto de vista é necessário 1) situar a psicologia ambiental entre as disciplinas a ela conectada; 2) precisar sua relação com essas disciplinas conexas, principalmente em termos de metodologia.

Na leitura das diferentes contribuições deste capítulo, parece haver um sub-entendido consensual a respeito do fato de que a Psicologia Ambiental é necessariamente uma disciplina interdisciplinar. Mas é preciso, realmente, seguir Proshansky, Ittelson e Rivlin (1970), e considerar que a Psicologia Ambiental é, por definição, uma disciplina interdisciplinar e que os psicólogos ambientais raciocinariam como psicólogos, o que entrava a sua necessá-

4 Este capítulo está baseado nas contribuições de E. Sanchez, O. Romice, D. Uzzell, H. Günther, E. Moyano e de mim mesmo. 
ria colaboração com outras disciplinas? Esta tomada de posição é curiosa por duas razões:

- primeiramente, isto faz da Psicologia Ambiental a única disciplina interdisciplinar que lida com o ambiente, impedindo-a, por isto mesmo, de se afirmar como uma abordagem singular e, portanto, disciplinar; e

- em segundo lugar, não é por causa de relações privilegiadas com outras disciplinas e de um olhar conjunto com outras disciplinas sobre um mesmo objeto que uma disciplina é interdisciplinar. Assim, por exemplo, a Psicologia do Desenvolvimento trabalha em estreita colaboração com os pediatras, mas não é interdisciplinar por causa disto.

H. Günther recorda que a Psicologia Ambiental implica em três campos de estudos que condicionam, cada um deles, uma colaboração com grupos de disciplinas diferentes: a Psicologia; o ambiente construído tal como pode ser estudado pelos arquitetos, pelos ergonomistas e pelos urbanistas no que se refere à cidade ou à paisagem; e os ambientes naturais tais como são estudados em biologia e em geologia. Resulta disto que não pode haver uma teoria ou metodologia universal capaz de dar conta do conjunto destes aspectos e de sua complexidade.

Para D. Uzzell, a interdisciplinaridade é uma qualidade essencial da psicologia ambiental por uma exigência da abordagem global do ambiente, mas também o lugar de todos os perigos. Com efeito, toda ação sobre o ambiente concerne não apenas ao ambiente em sua dimensão física, mas igualmente à sua dimensão social. Além disto, o autor observa muito justamente que as metodologias colocadas em ação não são independentes dos modelos da relação indivíduo-ambiente ao qual o pesquisador adere. Seguese daí ser de importância capital explicitar os modelos aos quais nos referimos. Os modelos de homem são, assim, um meio de comunicação com as outras disciplinas na medida me que eles permitem fornecer um quadro de referência à colaboração multidisciplinar. 
Não se pode menoscabar que a interdisciplinaridade é uma posição indispensável na resolução de problemas quando se aborda um objeto como o ambiente, para cujo estudo colaboram todo um conjunto de disciplinas: as ciências do homem e da sociedade, as Ciências da natureza e as Ciências de projeto (design), tais como a Arquitetura e o Urbanismo. A interdisciplinaridade exige uma colaboração sobre bases explícitas, e ela só funciona se as disciplinas que colaboram entre si fizerem-no em pé de igualdade. Não seguiremos $\mathrm{O}$. Romice que aconselha à Psicologia Ambiental não se colocar como prescritor mas lhe outorga um papel de informante. A Psicologia não pode ser nem informativa nem prescritiva; ela deve intervir em partes iguais com as outras disciplinas. A posição recíproca de igualdade é a única posição que garante uma verdadeira interdisciplinaridade. É apenas participando de todas as etapas de uma intervenção que ela adquire credibilidade. A Psicologia aporta uma abordagem original na medida em que se interesse pelo indivíduo, ser que pensa, que sente e que age em e ante um ambiente. A Psicologia Ambiental traz não apenas um olhar particular apoiado em seus próprios paradigmas; ela coloca igualmente em ação metodologias que lhe são próprias para apreender seu objeto ${ }^{5}$. Esta posição contribui para resolver problemas ambientais se ela se exprimir e se integrar como tal, e não ocorrer uma hierarquia entre as disciplinas. A Psicologia Ambiental apenas pode reivindicar uma posição forte se ela tiver crédito como uma disciplina. Em outros termos, ela deve possuir um corpo de conhecimentos conseqüente e teorias específicas; ela deve funcionar como uma disciplina acadêmica ao lado de outras disciplinas das ciências do homem e da sociedade. Ora, verifica-se nas contribuições de uns e de outros, que se recrimina à psicologia ambiental tanto ser por demais instrumentalizada, quer dizer, por demais preocupada com a aplicação, quanto ser por demais teórica, sem escutar suficientemente os problemas da sociedade. A Psicologia Ambiental deve ser ambas ao mesmo tempo, tanto endossando um posicionamento acadêmi-

5 Ao dirigir um olhar para os indivíduos, as metodologias realizadas pela Psicologia Ambiental se inspiram naquelas empregadas pela Psicologia, mas, contrariamente ao que sugere E. Moyano, não se limitam a elas, na medida em que são metodologias de campo ancoradas na relação com o espaço. 
co disciplinar quanto um posicionamento aplicado, onde a colaboração entre disciplinas é primordial.

Parece-nos que estes posicionamentos contraditórios quanto ao seu papel e ao seu lugar no meio de outras disciplinas que lidam com o ambiente testemunham a utilidade de nossa disciplina e, naturalmente, o fato de que, ainda jovem (cerca de trinta anos), ela deve conquistar o seu lugar ao lado de disciplinas a ela conectadas (as ciências do homem e da sociedade), como também ao lado das ciências de projeto (design), como a Arquitetura e o Urbanismo, assim como das ciências da natureza. Isto se revela ainda mais difícil pelo fato de que cada um destes grupos de disciplinas ter uma concepção própria de ambiente, o que ocasiona problemas de compreensão entre eles. Com efeito, entre uma concepção do ambiente como criado, agenciado e organizado pelo homem - da Arquitetura e no Urbanismo, como sistema biológico e físico-químico - das ciências da natureza, e como uma construção daquele que o percebe - das Ciências Sociais, as correspondências e os pontos de acordo são tênues.

\section{Pontos de referência para uma visibilidade política eficaz}

Este capítulo foi construído em torno das lacunas identificadas e nas estratégias a serem empreendidas de modo a contribuir para a construção do futuro proposto pelos diferentes autores. ${ }^{6}$ As proposições formuladas são, de fato, tanto de psicólogos ambientais, quanto de representantes da Arquitetura e do Urbanismo (L. Castello \& J-P. Thibault), disciplinas com as quais a Psicologia Ambiental tem tradicionalmente estreitos laços.

R. Gifford avalia que a contribuição da disciplina é pouco conhecida. Ele identifica três prioridades para a psicologia ambiental: a necessidade de aumentar o interesse pelo ambiente e a relação como o ambiente global; de colocar o acento sobre a educação ambiental, quer dizer, na ênfase em mu-

6 Este capítulo esta baseado nas contribuições de R. Gifford, L. Castello, Y. Bernard, E. Tassara, J-P. Thibault, R. Mira, D. Stea e S. Elguea. 
danças de atitudes e de comportamentos ante o ambiente; e de incitar os planejadores a considerar mais firmemente a planificação social.

L. Castello insiste quanto à necessidade de implicar as comunidades envolvidas nas transformações ambientais realizadas, e de trabalhar mais fortemente as interrelações entre as noções de lugar, de sítio e de povoamento, observando uma operacionalização muito frágil de certos conceitos teóricos. Y. Bernard convida a Psicologia Ambiental a se basear mais em análises sócio-demográficas, assim como em modos de vida de moradores, para identificar as necessidades referentes ao habitat, relacionando principalmente as temporalidades do habitat construído com as temporalidades dos ocupantes. Para E. Tassara, os desenvolvimentos próprios à globalização pedem definir uma Psicologia Ambiental do futuro construindo novos paradigmas que levem mais em conta a emancipação humana. J-P. Thibaud convida-nos a nos perguntarmos sobre o que entendemos por "ambiente" e a preocuparmo-nos com situações corriqueiras tanto quanto com situações de emergência. Quanto a R. Mira, D. Stea e S. Elguea, estes estimam que a psicologia ambiental esteve mais preocupada com os desenvolvimentos teóricos e acadêmicos do que com a difusão e com o relacionamento de seus conhecimentos com o mundo dos decisores, e identificam uma lacuna essencial na difusão das contribuições da Psicologia Ambiental: ela não sabe se impor junto aos políticos!

Além das questões formuladas à Psicologia Ambiental, perguntas que nos confortam pelo fato de que nossa disciplina tem um papel científico e social muito importante a ocupar, os diferentes participantes identificam, quase de maneira unânime, duas insuficiências: uma primeira se refere à falta de desenvolvimento de metodologias específicas à disciplina; uma segunda se refere a um defeito na Engenharia social ou sócio-ambiental.

- Nós não pensamos que haja um déficit de instrumentos em Psicologia Ambiental, mas antes um certo desconhecimento das metodologias disponíveis, tanto aquelas emprestadas dos geógrafos e dos urbanistas, quanto aquelas elaboradas por nossos colegas. Por outro lado, é verdade que as abordagens multi-metodológicas, que 
combinam cognições, emoções e comportamentos, não são tão frequientes quanto deveriam ser (cf. a exigência de uma abordagem holística da relação indivíduo-ambiente, mencionada por E. Wiesenfeld).

- Qualquer que seja o domínio de intervenção preconizado, a participação e a implicação das pessoas concernentes é primordial. Trata-se da utilização de técnicas com as quais a Psicologia Ambiental está mais ou menos familiarizada, na medida em que um bom número de psicólogos ambientais saíram ou tiveram uma formação em Psicologia Ambiental. Mas, será o papel da Psicologia Ambiental comprometer-se, além da resolução de problemas, na problemática da aceitação das medidas preconizadas? Esta questão remete, como sublinha V. Giuliani, à diferença, a meu ver essencial, entre pesquisa aplicada e pesquisa orientada no sentido de uma mudança, diríamos com K. Lewin, da pesquisa-ação. Isto responde ao desejo de L. Castello de uma evolução da psicologia ambiental em direção a um maior pragmatismo? Neste contexto, é possível distinguir três modos de funcionamento na psicologia ambiental, modos de funcionamento que são, bem entendido, interdependentes, e que se remetem a práticas profissionais específicas: 1) uma psicologia ambiental acadêmica, preocupada essencialmente com a sistematização dos conhecimentos relativos à relação indivíduoambiente; 2) uma psicologia ambiental estreitamente ligada à demanda social, assumindo uma posição de peritagem, e inscrevendo-se em um funcionamento de pesquisa aplicada, e 3) uma engenharia sócio-ambiental, correspondendo a uma pesquisa orientada, preocupada em acompanhar as mudanças introduzidas.

\section{4. À guisa de conclusão, um programa para o futuro}

Decididamente, a Psicologia Ambiental não é bastante visível, suas possíveis contribuições são mal identificadas e certas exigências, à qual ela 
está sujeita, testemunham uma assimilação de suas competências à psicologia social, que é apenas, recordemos, uma de suas diversas raízes. R. Gifford enumera um conjunto de desafios colocados para a psicologia ambiental neste começo de século: traduzir os resultados das pesquisa em prática; elaborar métodos de pesquisa mais apropriados; adquirir um corpo de conhecimentos mais coerente por meio da articulação teórica; desenvolver abordagens teóricas e integrá-las mais consistentemente; criar lugares apropriados; e, finalmente, promover a disciplina.

Parece-nos, além do mais, que uma noção em torno da qual as diferentes orientações da Psicologia Ambiental poderiam se encontrar, e isto de um modo consensual, não foi evocada no decorrer deste simpósio: a noção de qualidade de vida. Trata-se de uma noção transversal, a propósito da qual parece-me que poder-se-ia observar um certo consenso. Seja isto ao nível do espaço privado, da relação com os espaços partilhados, do habitat coletivo, do bairro, do lugar de trabalho, dos parques e espaços verdes, das cidades e de outros povoamentos, assim como da relação com o ambiente em sua totalidade, as intervenções utilizadas pela disciplina se referem a uma melhoria da qualidade de vida dos indivíduos envolvidos. Referir-se à noção de qualidade de vida posiciona a Psicologia Ambiental entre as disciplinas que contribuem à saúde e ao bem-estar do indivíduo, aumentando, assim, a sua vis ibilidade social.

Finalmente, a diversidade mostrada nos textos deste simpósio mostra que a psicologia ambiental está bem viva. Revela uma disciplina múltipla em suas abordagens, comprometida com os debates atuais da sociedade, e que tem, incontestavelmente, o seu lugar na paisagem científica deste século XXI, mesmo se, no momento atual, faltam-lhe, em certa medida, abordagens teóricas mais integrativas.

Moser, G. (2005). Environmental psychology: Competence and contours of a discipline - Comments based on the contributions. Psicologia USP, 16(1/2), 279-294. 


\begin{abstract}
This text presents a reflective and critical synthesis of the themes of the Symposium Psychology and Environment, as developed by the successive participants. It approaches, initially, the issue of the unity of Environmental Psychology, focusing on its object, role and utility. Next, it discusses Environmental Psychology between disciplinary affirmation and pluridisciplinary errancy. Focusing on the theme Environmental Psychology and Public Policies, it proposes benchmarks for efficient political visibility. Finally, it concludes by presenting a program for the future.
\end{abstract}

Index terms: Environmental psychology. Interdisciplinary research. Public policies.

Moser, G. (2005). La psychologie de l'environnement: compétence et scéma d'une discipline - commentaires a partir des contributions. Psicologia USP, 16(1/2), 279-294.

Résumé: Ce texte présente une synthèse réflexive et critique au sujet des thèmes du Symposium Psychologie et Environnement, ainsi que développés par les participants successifs. Il aborde initialement la question de l'unité de la Psychologie de l'Environnement, se concentrant sur son objet, son rôle et son utilité. Ensuite, il discute de la Psychologie de l'Environnement entre l'affirmation disciplinaire et l'errance pluridisciplinaire. Se concentrant sur le thème Psychologie de l'Environnement et Politiques Publiques, l'auteur propose des jalons de référence pour une visibilité politique efficace. Finalement, en guise de conclusion, il présente un programme pour le futur.

Mots-clés: Psychologie de l'environnement. Recherche interdisciplinaire. Politiques publiques.

\title{
Referências
}

Bonnes, M., \& Bonaiuto, M. (2002). Environmental psychology: From spatial-physical environment to sustainable development. In R. B. Betchel \& A. Churchman (Eds.), Handbook of environmental psychology (pp. 28-54). New York: John Wiley \& Sons. 
Canter, D. (1970). Architectutal psychology. London: Royal Institute of British Architects.

Darley, J. M., \& Gilbert, D. T. (1985). Social psychological aspects of environmental psychology. In G. Lindzey \& E. Aronson (Eds.), The handbook of social psychology (3rd ed.,Vol. 2). Reading, MA: Addison Wesley.

Getzel, J. W. (1975). Images of the classroom and visions of the learner. In T. G. David \& B. D. Wright (Eds.), Learning environments. Chicago: University of Chicago Press.

Moser, G., \& Uzzell, D. (2003). Environmental psychology. In T. Millon \& M. J. Lerner (Eds.), Comprehensive handbook of psychology. Vol. 5: Personality and social psychology (pp. 419-445). New York: John Wiley \& Sons.

Proshansky, H., Ittleson, W. H., \& Rivlin, L. G. (Eds). (1970). Environmental psychology. Man and his physical setting. New York: Holt, Rinehart \& Winston.

Stokols, D. (1978). Environmental psychology. Annual Review of Psychology, 29, 253295.

Recebido em 5.04.2004

Revisto e encaminhado em 23.02.2005

Aceito em: 7.03.2005 